American Journal of Applied Sciences 8 (2): 164-171, 2011

ISSN 1546-9239

(C) 2010 Science Publications

\title{
Assessing the Performance of Jordanian Educational Counselors in the Environment of Private and Government Schools toward Gifted Students
}

\author{
Ayed Hanna Ziadat \\ Department of Special Education, Princess Rahma College, \\ AL- Balqa Applied University, AL-Salt, Jordan
}

\begin{abstract}
Problem statement: The objective of this research was to evaluate the needs of suitable environment for educational counselors to provide support and enhance the capabilities of gifted students for better education and behavior performance during their academic school years. This study emphasizes with more details on the impact of the educational counselors experience, gender and schools environment regarding the role of improving gifted students performance in the country of Jordan. Approach: Seventy three educational counselors from government and private schools in the country of Jordon participated in the survey and completed the questionnaire in the spring of 2010. The questionnaire consisted of twenty two questions regarding the interaction between educational counselors and gifted students in private and government schools. Analysis of Variance was conducted on the mean of the sample population determined by counselors experience, gender and type of schools to verify the apparent differences of the means. The Statistical Package for Social Sciences (SPSS) program, T-Test and the F-Test were applied to the obtained data. Results: Performance of educational counselors in the private school environment was more effective and more evident than in government schools. The results of this study revealed that gifted students in private Jordanian schools, performed better in a climate characterized by high expectations of readiness to invest effort, enjoyment of learning, with strong disciplinary climate and good teacher-student relationships. Conclusion: Educational counselors with more years of experience showed more involvement in solving and enriching gifted students performance despite the gender of the counselor. Private schools provided better programs and more suitable environment for educational counselors to help gifted students than government schools.
\end{abstract}

Key words: Educational counselors, gifted students, Statistical Package for Social Sciences (SPSS), educational counselors, Attention Deficit Disorder (ADD), coupled motivation, Intelligence Quotients (IQ), Vocational Training Corporation (VTC)

\section{INTRODUCTION}

In order to highlight the significant variation in the performance of educational counselors at schools as it raises strong concerns about equality in the distribution of learning opportunities. Poor educational attainment comes at a high price for individuals and societies. The majority of students who have not completed school with an upper secondary qualification still face significantly poorer labor market prospects. This comes in support of the important role of educational counselors at schools to improve the quality of student's performance, which is in full agreement of the results of this research. More experience of educational counselors enriches the quality of student's performance at both public and private schools. It is worth mentioning that people's quality of life typically reflect directly on the educational system that efficiently meets today needs and the new generations to come (Ali and Mohammed, 2010; Focht and Abramson, 2009).
Gifted students learn more rapidly and comprehend more complex issues, with distinctive emotional needs. If a student displays exceptional traits, it is likely that he or she is gifted. Factors that set gifted students apart from their peers are a rich memory, reflectivity, inquisitiveness and openness to experiences.

A universal key in developing knowledge-rich schooling systems that can help students to learn better, teachers to teach better and schools to be more effective, lies in the quality of educational counselors, teachers and resources. The surrounding environment plays a significant role in implementing better educational programs and further enhancing capabilities of people's understanding (Marzooghi et al., 2009; Said et al., 2010).

Resnick et al. (1997) pinpointed out six categories to identify gifted students. The successful gifted student is an achiever and prefers to be consistent with the surrounding environment. The autonomous student is 164 
intrinsically motivated and passionate. The underground type is inhibited and exhibits low self-confidence. The challenging student is innovative and mischievous. The gifted dropout student is angry and explosive. The sixth type consist of the double-labeled students who are both gifted and disabled and sometimes labeled as having Attention Deficit Disorder (ADD) due to their lack of focus. As a result of the diversity and types of gifted students, regular school programs must be modified to accommodate their needs with better environment. The surrounding environment for gifted students should be regularly updated and modified with acceleration options and various forms of enrichment that broaden the conventional school curriculum. On the other hand, the role of educational counselors is imminent and essential for all types of gifted student's at all educational levels. Coordinating a comprehensive program to satisfy gifted students is an intricate task. Schools with direct involvement of educational counselors should generate opportunities such as acceleration, enrichment and advanced classes for gifted students. It is important to realize that if gifted students are taught in a traditional slow-paced classroom and subjected to an ineffective curriculum, the gifted students do not apply themselves, resulting in low stimuli, leading to even dropping out from schools.

Researchers and specialists have different opinions over the definition of gifted individuals; this is due to the fact that different groups concentrate on diverse potentials such as creativity, achievements and mental abilities to perform better under different conditions and circumstances, while others might focus on tests performance. Gifted students possess Excellencies in the performance in different fields of their life traits. AbdulWahab (2008) and Ziegler and Heller (2000) are in full agreement to one unified classification which coupled motivation and creativity as the main factors for gifted individuals. Strong and trusted relationships must be evident between educational counselors and their gifted students. The trust factor is the essential step that gifted students need to secure prior any initial progression as they would start presenting all different issues of concern to the counselor this is in full agreement with many researchers such as; (Focht and Talya, 2009; AL-Salameh et al., 2010).

Kesner (2005), measured teacher's perception and the relationship with their students, also the prospective of student's feedback regarding the teacher's performance and actions. The results showed a positive outcome from students and teachers alike in terms of full understanding of duties and responsibilities as well as mutual respect leading to further improvement of academic and personal skills. Many different types of tests for Intelligence Quotients (IQ) were developed over the years as an assessment of ability to think and reason in a standard way of comparing abilities among the majority of students within the same age group and at the same educational level. For example in 1904, Alfred Binet established the Binet-scale, which constituted a revolutionary technique to the assessment and evaluation of individual mental capabilities of performance (Rushton, 1997).

Educational counseling services are necessary for gifted students. The study of (Worthington and Dillon, 2011; Marzooghi et al., 2009; Altbach and Knight, 2007) recognized the importance to provide gifted students with sufficient counseling services, where a sample of African American gifted students were exposed to special programs. The results of performance before and after were compared leading to the conclusion of dramatic improvement in academic performance.

The objective of this research is to shed light on the important role and the essential needs for educational counselors in providing support and enhancing the capabilities of gifted students for better education and behavior performance during their academic school years. This study emphasizes with more details on the impact of the educational counselors experience, gender, school environment and responses to general and practical questions regarding the role of the counselors in recognizing and improving the gifted student performances. This also increases the experience of counselors concerning student problems, characteristics, policy-making and futures plans in education and curriculum related aspects to the care of the gifted students in order to avoid boredom and frustration which they may suffer through the regular educational system in schools (Majid and Alias, 2010; Schroth, 2007; and Boykin et al., 2005). It is essential in this fast changing world for individuals to enhance their proficiency and experience throughout their daily lives, education systems need to establish solid foundations for attaining education at all stages including developing skills in order to strengthen the capacity and motivation of young adults of the new generation to perform better during all levels of school and to continue their aim of education beyond basic schooling. 


\section{MATERIALS AND METHODS}

The Hashemite Kingdom of Jordan is an independent Arab country, Amman being the capital. The population of Jordan was estimated in 2004 to be 5.4 million inhabitants composed of 2.8 million males and 2.6 million females (Department of Statistics, 2004). Jordan is considered as a developing country with limited resources. Located in the center of the Middle East with a total territory of 60,000 square miles. It is south of Syria, southwest of Iraq, northwest of Saudi Arabia and east of the occupied West Bank.

An overview of the general education system in the Hashemite kingdom of Jordan: The general education principles in the country of Jordan are part of the Jordanian Constitution. The educational services are introduced to everyone in Jordan equally and without any discrimination based on sex, ethnicity, language, or religion. As every Jordanian has the right to free government education up to the high school level. According to the Ministry Of Education (MOE) in Jordan, the number of schools in all parts of the country reached 5526 with 76,946 teachers and 1,515.315 students, with almost even distribution of (49\%) females and $(51 \%)$ males. Government schools overtake the highest percentage of the total student's population in the country of Jordan reaching $70.5 \%$, followed by private schools 19.2 and $8.9 \%$ in the United Nations Relief and Works Agency schools and $1.4 \%$ distributed to other governmental institutions. Basic schooling is compulsory for all Jordanian students. The educational system in Jordan starts from kindergarten to the twelfth grade including basic primary, middle and secondary schools. The basic school consists of grades one to ten. At the end of the tenth grade the scores of each student for the previous three years are combined to determine in which secondary track students will continue. The secondary level starts from grades eleven and twelve as it is divided into two main tracks: one being an academic track. This track ends with a general secondary education examination called Tawjihi. The other is the vocational track. This track consists of vocational training preparing students for skilled labor, which is run by the Vocational Training Corporation (VTC) and the Ministry Of Education (MOE).

Study area: Al-Balqa Governorate is one of twelve governorates in the country of Jordan as shown in Fig. 1. Al- Balqa Governorate is located northwest of the capital city Amman with an area of $1076 \mathrm{Km}^{2}$ and population of 349,580 as of 2007 statistics (Department of Statistics, 2007).

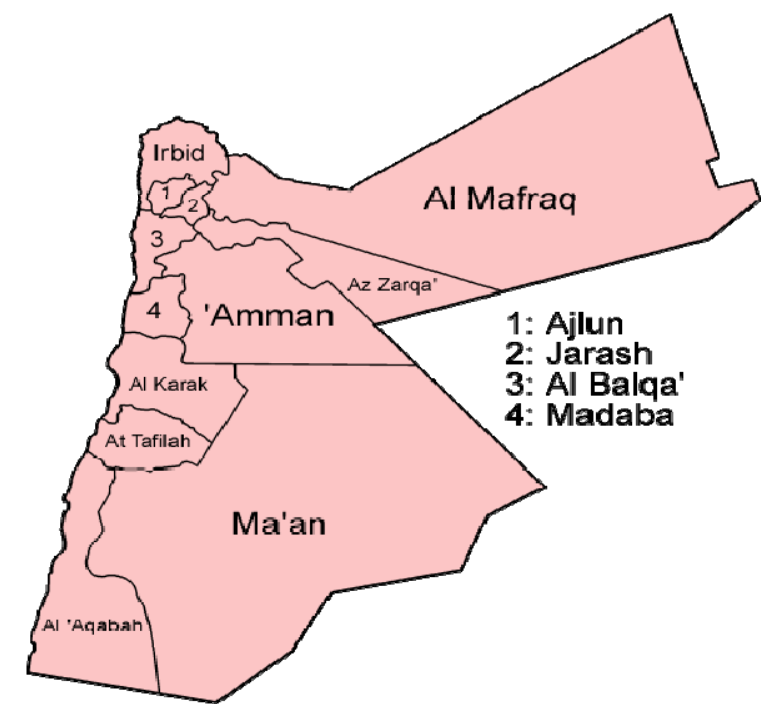

Fig. 1: Location of Governorates in the Hashemite Kingdom of Jordan

The total number of educational counselors working in Al-Balqa Governorate in the country of Jordon consist of one hundred and sixty four (male and female) at both private and government schools.

A total of seventy three educational counselors from the total sample group participated in the survey and completed the questionnaire in the spring of 2010.

The questionnaire consisted of twenty two questions regarding the interaction between educational counselors from different backgrounds and gifted students within the educational facilities, such as the type of services and consultations provided to gifted students, types of incentives, encouragements and disciplinary actions. These questions are presented in table two of the results and discussion section presented in this research. Analysis of Variance was conducted on the means of the sample populations determined by counselors experience, gender and type of schools, to verify the apparent differences of the means. The Statistical Package for Social Sciences (SPSS) program and the F-Test was applied on the obtained data.

The questionnaire was evaluated by professionals for its content, clarity of language and appropriateness of length prior to conducting the study survey using an initial draft form. Twenty individuals with a variety of backgrounds, education levels, age and gender from the same regional area were chosen for the draft evaluation. The pre-tested sample was excluded from the actual survey. The questionnaire was subsequently evaluated based on the pre-test and revised to its final format. 
Am. J. Applied Sci., 8 (2): 164-171, 2011

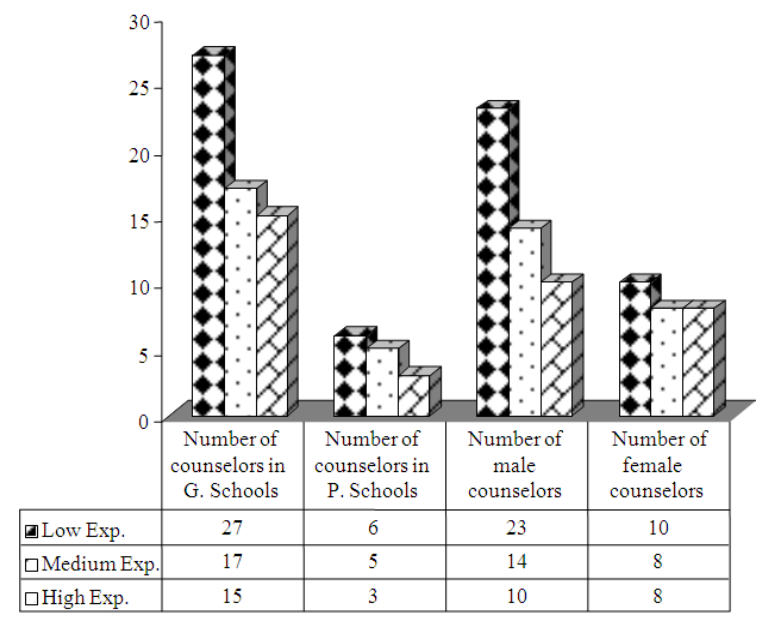

Fig. 2: Sample distribution according to the study variables of government and private schools (Level of experience and gender)

The test-retest reliability coefficient Cronpanch Alpha ( $\alpha)$ was used to test the reliability of the scale and the internal consistency of the questionnaire, which was calculated to be $(0.82)$. From the statistical perspective this is a reliable result as it exceeds 0.60 (George and Mallery, 2003). Also verification of the study stability was checked by applying it twice in a two-week period on 20 counselors (male and female) as excluded from the main sample group.

The sample group was divided according to gender, government or private schools and years of experience. The number of male counselors from government schools reached thirty six, while female counselors reached twenty three with a variety of experience ranging from three years to twenty five years. On the other hand, eleven male counselors and three female counselors were from private schools with a variety of experience ranging from two years to fifteen years.

Figure 2 provides the actual distribution of the educational counselors who participated in the survey, according to gender, type of schools and years of experience in educating gifted students. It is worth mentioning that five years or less of experience was ranked as low, mean while five to ten years experience as medium and above ten years categorized as high experience level.

\section{RESULTS}

Analysis of Variance was conducted on the mean of the sample populations determined by counselors experience, gender and type of school to verify that the apparent differences of the mean were statistically significant. The Statistical Package for Social Sciences
(SPSS) program and the F-Test was applied on the obtained data. Significant results were revealed regarding the important role of educational counselors in the academic performance of gifted students.

Table 1 presents the percentage in the descending order of importance of the questions as statically calculated regarding the role of educational counselors influence on gifted students. The calculated mean for the psychological services presented by counselors were calculated as 4.10 clearly ensures the important role that educational counselors takes on their behalf in guiding gifted students with direct influence on gifted students learning capabilities. These results are in full agreement with (Zeng et al., 2010; Komalasari, 2009; Kaskaloglu, 2007; Wood, 2006) which emphasizes on counseling as the essential tool for gifted students in order to enrich their capabilities and to flourish the intelligence within. Table 2 shows that the sum of the average educational counselor role in determining gifted students in private schools for low and medium experienced educational counselors were higher than in government schools as the mean reached (78.83) for low experience and (82.42) for medium experience educational counselors. On the other hand, educational counselors with high experience in determining gifted students in government schools were higher than those in private schools as the mean reached (79.53). This can be attributed to the different positions that high experienced educational counselors were appointed to throughout government schools in order to utilize the acquired experience in different locations as the experience in this field became essential and important at different levels of education for gifted students. Similar results were obtained by (Burandt, 2011; Khan, 2009; Keum-Hyeong et al., 2010; Baskin et al., 2010).

In order to evaluate the role of educational counselors on gifted students according to the variables of their experience, gender and types of schools, a triple analysis with single variable (Three-way ANOVA) was carried out as shown in Table 3 . Table 3 indicates a significant difference according to the experiences of educational counselors reaching (0.016). The statistical analysis in Table 4 shows a significant difference in favor of educational counselors performance in private schools toward gifted students in comparison to educational counselors in government schools at the level of $(\alpha=$ $0.05)$ in the country of Jordan. This is in full agreement with (Redzuan et al., 2010; Rosadah and Aliza, 2010).

This is due to the fact that private schools provide and encourage gifted students and their counselors through workshops, seminars and further special programs (Kazu, 2009; Buntod et al., 2010). Many counselors in private schools are sent to special training courses on the national and international levels including conferences to obtain better tools for improving the skills and methods of educating gifted students at all levels. 
Am. J. Applied Sci., 8 (2): 164-171, 2011

Table 1: Mean, standard deviations and the percentage of importance of the counselors role for gifted students arranged in descending order of importance

\begin{tabular}{|c|c|c|c|c|c|}
\hline $\begin{array}{l}\text { Question level } \\
\text { of Importance }\end{array}$ & Counselors duties and objectives & Mean & $\begin{array}{l}\text { Standard } \\
\text { deviation }\end{array}$ & $\begin{array}{l}\text { Percentage of } \\
\text { Importance } \\
\end{array}$ & $\begin{array}{l}\text { Level of } \\
\text { Importance }\end{array}$ \\
\hline 1 & The counselor provides psychological services to gifted students. & 4.10 & 0.74 & 80.8 & High \\
\hline 2 & Students have positive attitudes towards learning and education. & 3.96 & 0.86 & 77.0 & High \\
\hline 3 & Counselors encourage gifted students to cooperate and compete together. & 3.95 & 0.94 & 76.8 & High \\
\hline 4 & Counselors develop voluntary work among gifted students. & 3.85 & 0.99 & 74.8 & High \\
\hline 5 & Counselors train gifted students for creative thinking skills. & 3.79 & 1.04 & 74.0 & High \\
\hline 6 & The counselor provides physical and heath care to gifted students. & 3.79 & 1.01 & 73.8 & High \\
\hline 7 & Provide students needs towards achievements and success. & 3.79 & 0.91 & 73.6 & High \\
\hline 8 & Guides students towards the best type of learning. & 3.78 & 0.96 & 73.4 & High \\
\hline 9 & Provides incentives to encourage gifted students. & 3.75 & 1.09 & 73.0 & High \\
\hline 10 & $\begin{array}{l}\text { Encourage gifted students to visit libraries in order to } \\
\text { increase their cultural awareness. }\end{array}$ & 3.74 & 1.01 & 72.6 & High \\
\hline 11 & Guides gifted students towards additional curriculum. & 3.73 & 1.02 & 72.0 & High \\
\hline 12 & Develops new strategies of thinking in gifted students. & 3.71 & 1.05 & 71.2 & High \\
\hline 13 & Provides basic learning which help gifted students with new ideas. & 3.68 & 0.99 & 71.0 & High \\
\hline 14 & Conducts individual interviews with parents of gifted students. & 3.66 & 0.98 & 70.2 & High \\
\hline 15 & Organizes regular meeting with gifted students. & 3.66 & 1.06 & 69.6 & Medium \\
\hline 16 & Organizes social activities with gifted students. & 3.64 & 1.00 & 69.4 & Medium \\
\hline 17 & Deals with obstacles that might limit creativity of gifted students. & 3.59 & 1.09 & 66.8 & Medium \\
\hline 18 & Organizes leisure time programs for gifted students. & 3.52 & 1.07 & 66.6 & Medium \\
\hline 19 & Organizes scientific competitions for gifted students. & 3.48 & 1.16 & 63.8 & Medium \\
\hline 20 & $\begin{array}{l}\text { Organizes visits to scientific institutions in order to enhance } \\
\text { motivation among gifted students. }\end{array}$ & 3.40 & 1.30 & 63.6 & Medium \\
\hline 21 & $\begin{array}{l}\text { Provides enriched programs especially in languages, science, mathematics, } \\
\text { and computers for gifted students. }\end{array}$ & 3.34 & 1.09 & 63.0 & Medium \\
\hline 22 & Develops special programs to improve the abilities of gifted students. & 3.32 & 1.22 & 60.0 & Medium \\
\hline
\end{tabular}

Table 2:Mean, standard deviations and the percentage of importance of the educational counselors role for gifted students according to sex, years of experience and the type of school

\begin{tabular}{|c|c|c|c|c|c|}
\hline Gender of counselor & Counselor experience & Type of school & Mean & Standard deviation & Count \\
\hline \multirow[t]{9}{*}{ Male } & \multirow[t]{2}{*}{ Low } & Government & 75.40 & 16.72 & 20 \\
\hline & & Private & 77.30 & 9.29 & 3 \\
\hline & \multirow[t]{2}{*}{ Medium } & Government & 78.77 & 10.25 & 9 \\
\hline & & Private & 82.40 & 12.25 & 5 \\
\hline & \multirow[t]{2}{*}{ High } & Government & 80.57 & 15.20 & 7 \\
\hline & & Private & 70.00 & 44.54 & 3 \\
\hline & \multirow[t]{3}{*}{ Total } & Government & 77.25 & 14.86 & 36 \\
\hline & & Private & 77.63 & 22.42 & 11 \\
\hline & & Total & 77.34 & 16.65 & 47 \\
\hline \multirow[t]{7}{*}{ Female } & \multirow[t]{2}{*}{ Low } & Government & 80.14 & 6.46 & 7 \\
\hline & & Private & 80.33 & 14.01 & 3 \\
\hline & Medium & Government & 77.87 & 6.05 & 8 \\
\hline & High & Government & 78.62 & 10.97 & 8 \\
\hline & \multirow{3}{*}{ Total } & Government & 78.82 & 7.89 & 23 \\
\hline & & Private & 80.33 & 14.01 & 3 \\
\hline & & Total & 79.00 & 8.41 & 26 \\
\hline \multirow[t]{9}{*}{ Sum } & \multirow[t]{2}{*}{ Low } & Government & 76.62 & 14.80 & 27 \\
\hline & & Private & 78.83 & 10.75 & 6 \\
\hline & \multirow[t]{2}{*}{ Medium } & Government & 78.35 & 8.29 & 17 \\
\hline & & Private & 82.42 & 12.25 & 5 \\
\hline & \multirow[t]{2}{*}{ High } & Government & 79.53 & 12.66 & 15 \\
\hline & & Private & 70.00 & 44.54 & 3 \\
\hline & \multirow[t]{3}{*}{ Total } & Government & 77.86 & 12.54 & 59 \\
\hline & & Private & 78.21 & 20.45 & 14 \\
\hline & & Total & 77.93 & 14.22 & 73 \\
\hline
\end{tabular}

Table 3: Results of (Three-way ANOVA) variances, gender and years of experience regarding the role of educational counselors of gifted students

Resources of Sum of Degree of Mean square F - $\quad$ Statistical

\begin{tabular}{lll} 
variance & squares freedom value Value Indication(sig.) \\
\hline
\end{tabular}

\begin{tabular}{lllllll}
\hline Gender & 206.60 & 1 & 206.60 & 0.788 & 0.378
\end{tabular}

$\begin{array}{lllll}\text { Experience } & 2303.002 & 1151.50 & 4.392 & 0.016\end{array}$
Table 4: Results of the t-test regarding the educational counselor's performance according to the type of school

\begin{tabular}{lllllll}
\hline $\begin{array}{l}\text { Type of } \\
\text { School }\end{array}$ & $\begin{array}{l}\text { No. of } \\
\text { counselors Mean }\end{array}$ & $\begin{array}{l}\text { Std. } \\
\text { deviation }\end{array}$ & T- test & df & Sig. \\
\hline Government & 59 & 77.86 & 12.54 & 5.64 & 71 & 0.0 \\
Private & 14 & 97.92 & 8.81 & & & \\
\hline
\end{tabular}


Am. J. Applied Sci., 8 (2): 164-171, 2011

Table 5: Comparisons of the mean differences due to the experience variables among educational counselors

\begin{tabular}{llllllr}
\hline & & & & $95 \%$ Confidence interval \\
Experience & Experience & Mean & Std. & & Lower & Upper \\
(I) & $(\mathrm{J})$ & Difference $(\mathrm{I}-\mathrm{J})$ & Error & Sig. & Bound & Bound \\
\hline Low & Medium & -02.24 & 4.45 & 0.88 & -13.39 & 08.91 \\
& High & $-14.30^{*}$ & 4.74 & 0.01 & -02.61 & -02.42 \\
Medium & Low & 02.24 & 4.45 & 0.88 & -08.91 & 13.39 \\
& High & -01.20 & 5.14 & 0.07 & -24.93 & 00.81 \\
High & Low & $14.30^{*}$ & 4.74 & 0.01 & 02.42 & 26.17 \\
& Medium & 01.20 & 5.14 & 0.07 & -00.81 & 24.93 \\
\hline
\end{tabular}

*: The mean difference is significant at 0.05 levels

To determine the impact of the level of experience among the educational counselors role for gifted students, further statistical analysis was conducted on the mean differences of the experience level as shown in Table 5. It is clear that a significant difference was between the low and medium experienced educational counselors, as the impact of the role of experienced educational counselor is more evident than with low experienced counselors.

\section{DISCUSSION}

All participants in the survey agreed on the important role of educational counselors in providing psychological services to gifted students as this question obtained the highest approval rate reaching $80.8 \%$ of all the questions presented in the questionnaire.

The statistical analysis at the level of $(\alpha=0.05)$ revealed that there are no differences in the role of educational counselors due to the variances of sex. This is due to the fact that the educational counselors for gifted students stay at the same level without any further improvement and development of skills due to the shortages of training programs, seminars and workshops that must be offered on regular bases to educational counselors in both government and private school. This is in full agreement with (Fischer, 2011; Ahmad et al., 2010; and Bakar and Ishaka, 2010).

It is worth mentioning that the standard deviation calculated for questions $(9,10,17,18,20$ and 22) shown in Table (2) indicates that the shortages of financial resources limits the types of incentives available for gifted students as well as the shortages of extracurricular activities. With the same prospective, the limited number of libraries, resources and tools that fits the gifted student's needs restricts their cultural expansion and awareness (Worthington and Dillon, 2011; Gambo and Yusuf, 2010).

The statistical analysis of questions number $(2,6,8$ and 16) in Table (2) indicates that the gifted students are capable and eager to learn new techniques through different strategies as presented by the trusted educational counselors approach.
The performance of educational counselors at Jordanian schools revealed that excellence in education is an attainable goal, at reasonable cost. Equally important is that some schools show that it is possible to combine high performance levels of educational counselors with a socially equitable distribution of learning opportunities among gifted students. Educational counselors can make an important difference to performance orientation in education. The results of this research indicates that gifted students in private Jordanian school environment perform better in a climate characterized by high expectations and the readiness to invest effort, the enjoyment of learning, a strong disciplinary climate and good teacher-student relations. Among these aspects, gifted students perception of counselor-student relations and classroom disciplinary environment display the strongest relationships with student performance (Maidin and Hamzah, 2010; Fischer, 2011).

\section{CONCLUSION}

The following conclusions of this research can be summarized as follows:

- The results of this study showed the important role of educational counselors in a third world country in providing psychological services which has a positive effect on improving the learning capabilities of gifted students.

- Performances of educational counselors in private school environment were more effective and more evident than in government schools. This is due to the fact that in third world countries, private schools provide educational counselors with workshops, seminars and further special programs. In private schools a designated budget is implemented for further improvements of educational counselors at all levels. On the other hand, educational counselors with more years of experience showed more involvement in solving and enriching gifted students performance despite the gender of the counselor 
- Results from this research demonstrate that the challenge of achieving a high and equitable distribution of learning outcomes through highly experienced educational counselors can be addressed and to set ambitious goals for other educational counselors with less experience or lower level of educational training

- The results of the questionnaire presented in this research, indicated that some private Jordanian schools established strong educational standards as mere yardsticks and introduced performance benchmarks that the gifted students at particular age or grade levels should reach

Recommendations: As a result of this research, the following recommendations can be concluded:

- In order to offer excellent quality of learning at Jordanian schools, teachers, administrators and counselors must depend on the right policy framework within the institutional context. Such issues entail formulating educational objectives and standards for gifted students by monitoring commitments to these and feeding results back to the Ministry of Education, establishing rewards, support systems and consequences that flow by combining governance structures that transmits responsibilities to the front line (teachers, educational counselors and administrators at schools) with an equitable distribution of learning opportunities for gifted students

- In order to improve the performance of educational counselors in private and government schools in third world countries, regular and frequent training programs for educational counselor must be implemented and mandatory for all levels

- An annual budget should be allocated for establishing curricula for gifted students at all levels to cover different activities

- Exploring further cooperation with international organizations in order to obtain grants and more support for improvements of educational counselors as well as gifted students through different programs

- Establishing competitive programs for gifted students with incentives in all areas of studies would lead to better educational performance among gifted students

- Further studies on the performance of gifted students, linked to different variables such as place of residency, living standards and the cultural impact is recommended for better understanding of gifted students in the country of Jordan

\section{REFERENCES}

Abdul-Wahab, S.A., 2008. A preliminary investigation into the environmental awareness of the Omani public and their willingness to protect the environment. Am. J. Environ. Sci., 4: 39-49. DOI: 10.3844/ajessp.2008.39.49

Ahmad, N.A., Z.M. Jelas and M.M. Ali, 2010. Understanding students performance based on gender and types of schooling using SEM. Procedia-Social Behav. Sci., 7: 425-429. DOI: 10.1016/j.sbspro.2010.10.058

AL-Salameh, E.M., A.H. Ziadat and M.M. Attiat, 2010. The impact of structure and meaning in reading comprehension among gifted students. J. Applied Sci., 10 : 1923-1929. $\quad$ DOI: 10.3923/jas.2010.1923.1929

Altbach, P.G. and J. Knight, 2007. The internationalization of higher education: motivations and realities. J. Stud. Int. Edu., 11: 290-305. DOI: 10.1177/1028315307303542

Bakar, A.Y.A. and N.M. Ishaka, 2010. Counselling issues of gifted students attending a school holiday residential program: A Malaysian experience. Procedia-Social Behav. Sci., 7: 568-573. DOI: 10.1016/j.sbspro.2010.10.076

Baskin, T.W., C.D. Slaten, C. Sorenson, J. GloverRussell and D.N. Merson, 2010. Does youth psychotherapy improve academically related outcomes? A meta-analysis. J. Counsel. Psychol., 57: 290-296. DOI: 10.1037/a0019652

Boykin, A.W., A.A. Tyler, M. Kenneth, E.A. Hurley and C.T. Bailey et al., 2005. Culture-based perceptions of academic achievement among lowincome elementary students. Cultural Diversity Ethnic Minority Psychology, 11: 339-350. DOI: 10.1037/1099-9809.11.4.339

Buntod, P.C., P. Suksringam and A. Singseevo, 2010. Effects of learning environmental education on science process skills and critical thinking of Mathayomsuksa 3 students with different learning achievements. J. Soc. Sci., 6: 60-63. DOI: $10.3844 /$ jssp. 2010.60 .63

Burandt, S., 2011. Effects of an educational scenario exercise on participants' competencies of systemic thinking. J. Soc. Sci., 7: 52-62. DOI: $10.3844 /$ jssp. 2011.54 .65

Department of Statistics, 2004. The Hashemite Kingdom of Jordan. Jordan Figures, 6: 31-42.

Department of Statistics, 2007. The Hashemite Kingdom of Jordan. http://www.kinghussein.gov.jo/jordan.html 
Fischer, D., 2011. Monitoring educational organizations' culture of sustainable consumption: Initiating and evaluating cultural change in schools and universities. J. Soc. Sci., 7: 63-75. DOI: 10.3844/jssp.2011.66.78

Focht, W. and C.I. Abramson, 2009. The case for interdisciplinary environmental education and research. Am. J. Environ. Sci., 5: 124-129. DOI: 10.3844/ajessp.2009.124.129

Focht, W. and H. Talya, 2009. Evolution of a graduate environmental science program. Am. J. Environ. Sci., 5: 130-139. DOI: 10.3844/ajessp.2009.130.136

Gambo, A.I. and M.W. Yusuf, 2010. An application of multivariate analysis in modeling students placement in nigerian higher institutions. J. Math. Stat., $\quad 6$ : $\quad 350-356 . \quad$ DOI: 10.3844/jmssp.2010.350.356

Kaskaloglu, E.A., 2007. Public to charter: Accounts of gifted students. PhD Thesis, Arizona State University. http://gradworks.umi.com/32/87/3287966.html

Kazu, I.Y., 2009. The effect of learning styles on education and the teaching process. J. Soc. Sci.., 5:2, 85-94. DOI: 10.3844 /jssp.2009.85.94

Kesner, J.E., 2005. Gifted childrens relationships with teachers. Int. Educ. J., 6: 218-223.

Keum-Hyeong, C., B. Wendy and J. Bonita, 2010. Evaluation of counseling outcomes at a university counseling center: The impact of clinically significant change on problem resolution and academic functioning. J. Counsel. Psychol., 57: 297-303. DOI: 10.1037/a0020029

Khan, Z.N., 2009. Cognitive and non-cognitive characteristics as determinants of success in professional courses at undergraduate stage. J. Soc. Sci., 5: 212-215. DOI: 10:3844/jssp.2009.212.215

Komalasari, K., 2009. The effect of contextual learning in civic education on students' civic competence. J. Soc. Sci., 5: 261-270. DOI: 10.3844/jssp.2009.261.270

Maidin, N.F. and M.I.M. Hamzah, 2010. Learning to develop creativity and innovation: A case study of selected schools. Procedia-Social Behav. Sci., 7: 24-31. DOI: 10.1016/j.sbspro.2010.10.004

Majid, R.A. and A. Alias, 2010. Consequences of risk factors in the development of gifted children. Procedia-Social Behav. Sci., 7: 63-69. DOI: 10.1016/j.sbspro.2010.10.010
Marzooghi, R., R. Sheikholeslami and B. Shamshiri, 2009. Comparing achievement goal orientations of iranian gifted and nongifted schoolchildren. J. Applied Sci., 10: 1991-1993. DOI: 10.3923/jas.2009.1990.1993.

Redzuan, M., R.B. Juhari, F. Yousefi, M.B. Mansor and M.A. Talib, 2010. The relationship between gender, age, depression and academic achievement. Current Res. Psychol., 1: 61-66. DOI: 10.3844/crpsp.2010.61.66

Resnick, M.D., P.S. Bearman, R.W. Blum, K.E. Bauman and K.M. Harris, 1997. Protecting adolescents from harm. Findings from the national longitudinal study on adolescent health. J. Am. Med. Assoc., 278: 823-832.

Rushton, J.P., 1997. Race, intelligence, and the brain: The errors and omissions of the 'revised' edition of S. J. Gould's the Mismeasure of Man (1996). Personal. Individual Diff., 23: 169-180. DOI: 10.1016/S0191-8869(97)80984-1

Said, D.M., A.S. Mazahreh, H. Hammad, A.F. AlShawabkeh and K.S. Al-Saraireh, 2010. Effect of raising the environmental awareness on reducing kitchen water consumption by Jordanian families living in Amman City. Am. J. Applied Sci., 7: 1123-1128. DIO: 10.3844/ajassp.2010.1123.1128

Schroth, S.T., 2007. Perceptions of gifted programming: Degree of alignment in administrator, teacher, and gifted specialist beliefs. $\mathrm{PhD}$ Thesis, University of Virginia. http://gradworks.umi.com/32/35/3235117.html

Wood, S., 2006. Gifted and talented adolescents experiences in school counseling. PhD Thesis, The College of William and Mary. http:/gradworks.umi.com/32/09/3209552.html

Worthington, R.L. and F.R. Dillon, 2011. Deconstructing multicultural counseling competencies research: comment on owen, leach, wampold, and rodolfa (2011). J. Counsel. Psychol., 58: 10-15. DOI: $10.1037 / \mathrm{a} 0022177$

Zeng, H.Z., R.W. Leung and M. Hipscher, 2010. An examination of teaching behaviors and learning activities in physical education class settings taught by three different levels of teachers. J. Soc. Sci., 6: 18-28. DOI: 10.3844 /jssp.2010.18.28

Ziegler, A. and K.A. Heller, 2000. Effects of an attribution retraining with female students gifted in Physics. J. Educ. Gifted, 23: 217-243. DOI: $10.4219 /$ jeg-2000-572 